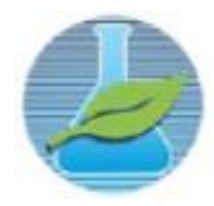

JCEC/REQ ${ }^{2}$

Journal

ISSN: 2446-9416

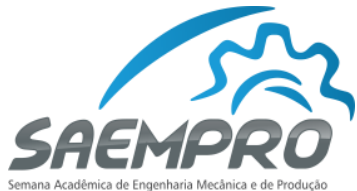

"EU, A INDÚSTRIA E O MUNDO"

08 a 11 de novembro de 2016 no campus Viçosa da UFV

Departamento de Engenharia de Produção e Mecânica - DEP

Universidade Federal de Viçosa - UFV

\title{
GESTÃO DO PROCESSO DE INOVAÇÃO EM EMPRESAS DE BASE TECNOLÓGICA NO ÂMBITO DO PROGRAMA TECNOVA
}

\author{
Larissa de Oliveira Atalla \\ Universidade Federal de Viçosa, Departamento de Engenharia de Produção e Mecânica \\ $\mathrm{Ph}$. Rolfs s/n - 36570-000 - Viçosa - MG \\ larissa.atalla@ufv.br, larissa.atalla@gmail.com
}

\section{INTRODUÇÃO}

A inovação é um fator fundamental para o crescimento econômico. Diante disso, é importante que as empresas tenham um sistema de gestão da inovação bem estruturado, que envolva indivíduos, tecnologias e a satisfação dos clientes para garantir produtos inovadores de qualidade e atrair nova clientela no mercado. O Programa TECNOVA, uma parceria entre a Fundação de Amparo à Pesquisa de Minas Gerais - FAPEMIG e a Financiadora de Estudos e Projetos - FINEP, tem o objetivo de fomentar a inovação em microempresas e empresas de pequeno porte no Estado de Minas Gerais. Além disso, existem leis e políticas públicas que incentivam a inovação nas empresas, porém estas ainda são insuficientes, pois existem dificuldades enfrentadas pelas pequenas e médias empresas para inovar, como: recursos, financiamentos, informações sobre entidades financiadoras, pessoal capacitado e ferramentas facilitadoras do processo de inovação. Tais dificuldades contribuem para que o processo de inovação não ocorra com muita frequência.

\section{OBJETIVOS}

Este trabalho objetiva analisar os resultados obtidos sobre a implantação do Sistema de Gestão da Inovação nas empresas participantes do Programa TECNOVA no período de março de 2015 a fevereiro de 2016.

\section{METODOLOGIA}

A metodologia de pesquisa utilizada foi a pesquisa-ação. Também foram realizados workshops de capacitação dos empresários e assessoramento remoto para auxiliar na utilização das ferramentas facilitadoras do processo de implantação do Sistema de Gestão da Inovação - SGI.

\section{RESULTADOS}

Como resultados da pesquisa, tem-se o desenvolvimento do Sistema EPR e os resultados alcançados com a utilização das ferramentas facilitadoras de implantação do Sistema de Gestão da Inovação, descritos a seguir.

\subsection{Sistema EPR - Estratégias, Projetos e Resultados}

O Sistema EPR foi criado com o objetivo de facilitar a inserção do processo de inovação na rotina das empresas participantes do Programa TECNOVA a partir da inter-relação e interação de etapas cruciais que devem ser analisadas nesse processo. Ele integra Estratégias, Projetos e Resultados de inovação abrangendo: Estrutura Analítica de Negócios - EAN, desafios de inovação, identificação, seleção e desenvolvimento de projetos, verificação dos resultados e melhoria do 


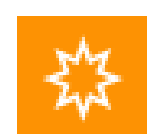

DESAFIOS

DE InUVACAO

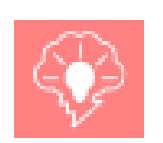

IDENTIFICAÇO DE PAOJETOS

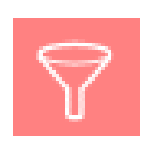

SELECANO

DE PROJETOS

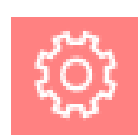

Moprojeten

\section{DFunguplo}

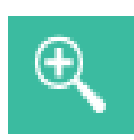

VERIFICAÇĀO DCS RESULTADOS

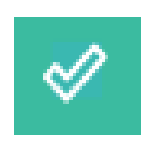

MELhosiA DO SISTEM

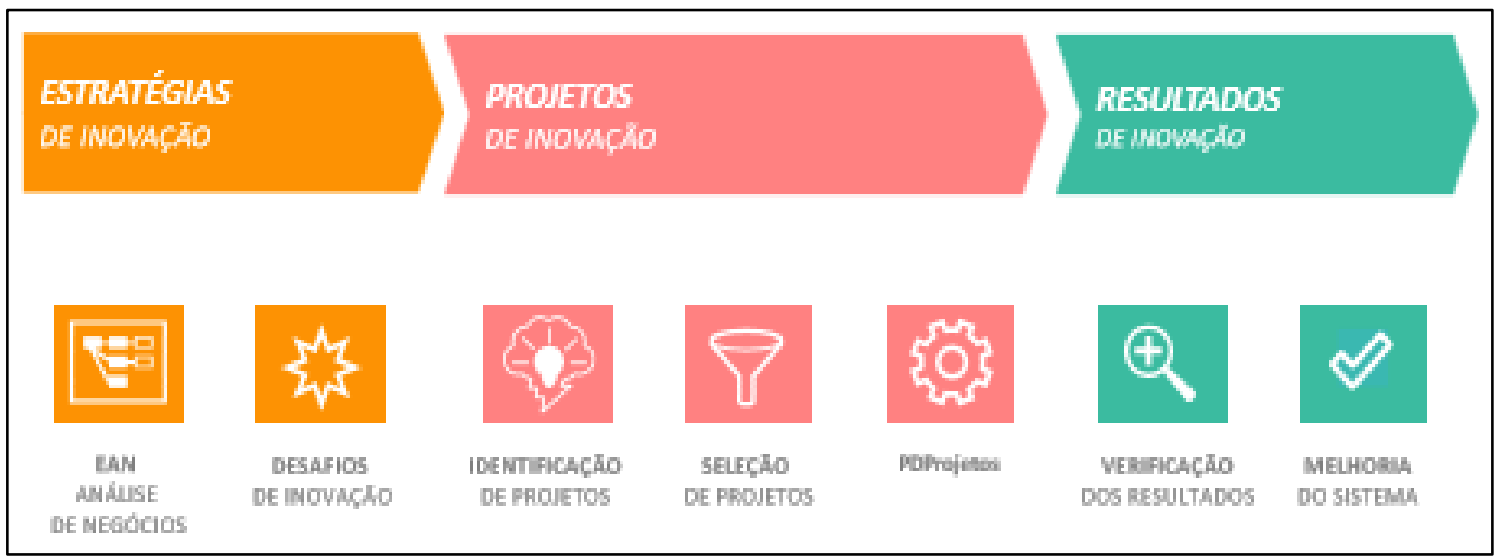

Figura 1 - Sistema EPR - Estratégias, Projetos e Resultados (NTG)

\subsection{Plano Tecnológico - Ptec:}

Outra ferramenta utilizada para auxiliar no processo de implantação do Sistema de Gestão da Inovação foi o Plano Tecnológico. Ele visa a articulação entre Tecnologia, Produto e Mercado TPM, além de ser extremamente importante para o Processo de Desenvolvimento de Produtos PDP, uma vez que busca sistematizar as etapas do processo com ações que seguem uma ordem cronológica pré-estabelecida para projetar e construir um produto com qualidade e de maneira eficiente, com o mínimo de retrabalho e desperdício de recursos.

\subsection{Outros Resultados}

A Figura 2 ilustra alguns resultados obtidos durante o período de março de 2015 a fevereiro de 2016: 


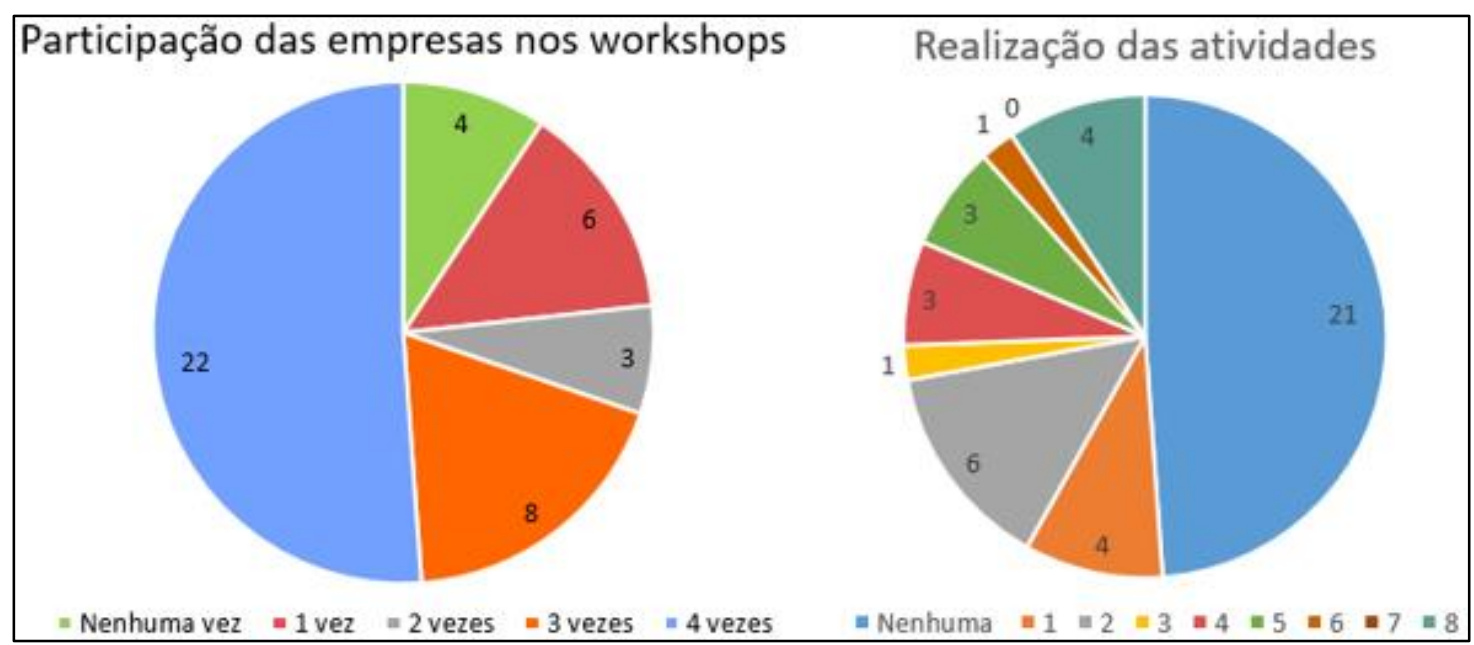

Figura 2 - Resultados da participação em workshops e realização de atividades (elaborado pelo autor)

Por meio de uma pesquisa, realizou-se um levantamento do número de empresas que utilizavam o Sistema EPR e quantas haviam iniciado o processo de implantação do SGI. O resultado pode ser observado na Tabela 1:

Tabela 1 - Utilização do Sistema EPR e implantação do SGI (elaborado pelo autor)
\begin{tabular}{|c|c|}
\hline Empresas que participaram da pesquisa & 14 \\
\hline Utilizam o Sistema EPR & 9 \\
\hline Não utilizam o Sistema EPR & 5 \\
\hline Empresas que não participaram da pesquisa & 29 \\
\hline Empresas que iniciaram a implantação do SGI & 15 \\
\hline Empresas que não iniciaram a implantação do SGI & 28 \\
\hline
\end{tabular}

Além dos dados apresentados acima, observou-se que das 11 etapas de implantação do SGI que deveriam ser feitas em cada empresa apenas $9 \%$ delas haviam sido concluídas enquanto que $91 \%$ ainda teriam que ser implantadas.

\section{CONCLUSÕES}

Através dos resultados obtidos observou-se que 51\% das empresas participaram dos 4 workshops realizados, e destas, $49 \%$ não realizaram nenhuma atividade pós-workshop. Supõe-se, para tais resultados, que as empresas inovam seus produtos ainda que de forma desestruturada, ou ainda, que a metodologia proposta está além das necessidades das empresas. Apesar disso, a metodologia desenvolvida pela equipe NTG, poderá auxiliar as empresas no desenvolvimento de seus produtos, bem como ser utilizada para melhorar a capacidade gerencial e o desenvolvimento das mesmas diante de novas oportunidades.

\section{AGRADECIMENTOS}

A Prof ${ }^{a}$. Dr ${ }^{a}$. Adriana Ferreira de Faria pela oportunidade de trabalhar nesse projeto e adquirir novos conhecimentos importantes para minha formação acadêmica e pessoal.

Ao Prof. Dr. Marco Antônio Sartori pelo suporte oferecido no pouco tempo que lhe coube.

Ao Marcos Fernandes de Castro Rodrigues pelo suporte oferecido durante o projeto, pelas suas correções e incentivos.

\section{REFERÊNCIAS}

CORAL, E.; OGLIARI, A.; ABREU, A. F. "Gestão Integrada da Inovação: Estratégia, Organização e Desenvolvimento de Produtos", 2009. 